\title{
DIVERSIDADE LINGUISTICA NO PARÁ: MUNDOS DE LÍNGUAS INDÍGENAS E DE LÍNGUA PORTUGUESA
}

\section{Marília de Nazaré FERREIRA-SILVA ${ }^{11}$ UNIVERSIDADE FEDERAL DO PARÁ marilia@ufpa.br}

Ana Carla Costa Castilho, Ana Cláudia Assunção Chaves Camila Néo Pereira, Rafaela Viana Maciel Milene das Mercês Alcântara, Sindy Rayane Ferreira de Souza ${ }^{22}$

Resumo: O Pará, parte da Amazônia, é uma das regiões brasileiras com grande concentração de línguas indígenas que vivem lado a lado com diversas variedades da língua portuguesa e outras línguas estrangeiras (o japonês, falado no município de Tomé-Açu, o italiano) e a Lingua Brasileira de Sinais (LIBRAS). Essa diversidade linguística se apresenta envolta em manifestações culturais e literárias várias que refletem também a diversidade social regional. Assim, a criação de um grupo PET/ Conexões de Saberes de Letras/Lingua Portuguesa (LP), na UFPA, teve como foco a educação sociolinguística, visando ampliar o conhecimento dessa diversidade linguística e literária no Pará, e de tópicos relacionados, tais como o bilinguismo, o multilinguismo, o contato entre línguas e o preconceito linguístico. O objetivo central do PET é proporcionar aos alunos de Letras a aquisição e o aprofundamento de conhecimentos específicos de sua área de atuação profissional, oportunizando a partilha desses saberes com comunidades populares. O conhecimento cientifico poderá ser multiplicado, então, chegando a recônditos que jamais seriam alcançados, senão por meio de ações que promovem a ampla circularidade e troca de saberes. Direcionado a estudantes oriundos de comunidades populares urbanas, o PET de Letras visa alcançar a comunidade de um modo geral, democratizando o acesso a bens culturais.

Palavras-chave: Amazônia. Diversidade. Línguas indígenas. LIBRAS. Comunidades populares.

${ }^{1}$ Doutora em Linguística pela UNICAMP desde 2003. Professora Associada da Universidade Federal do Pará, vinculada à Faculdade de Letras. Tutora do PET Letras/ Língua Portuguesa.

${ }^{2}$ Bolsistas do grupo PET Letras/Língua Portuguesa. Graduandas do curso de Licenciatura em Letras, habilitação em Língua Portuguesa da Faculdade de Letras, Universidade Federal do Pará. 


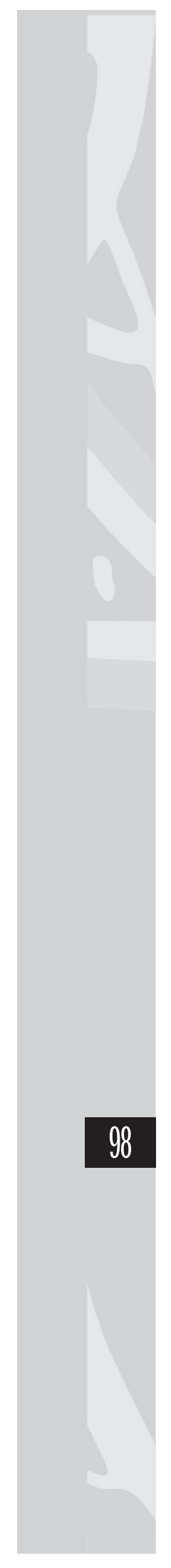

\begin{abstract}
The state of Pará, part of the Amazon Forest, is one of the Brazilian regions with representative concentration of indigenous languages, which integrates many diversities of Brazilian Portuguese and others foreign languages, besides LIBRAS (Brazilian Sign Language). This linguistic diversity is involved in various cultural and literary manifestation wich also reflet the social and regional diversity. Thus, the creation of a group called "PET/Conexões de saberes de Letras/ Lingua Portuguesa (LP), at UFPA, focusing on Sociolinguistics education, aiming to expand the knowledge on this linguistic and literary diversity in Pará, and other related topics like bilingualism, multilingualism, the interlanguage and the linguistic prejudice.
\end{abstract}

Keywords: Amazon. Diversity. Indigenous languages. LIBRAS. Popular communities.

\title{
Introdução
}

A sociolinguística surgiu em um contexto marcado por transformações nos estudos linguísticos. No início do século XX, Ferdinand de Saussure apresentou uma definição para as noções de língua e fala, tendo priorizado a língua como o objeto de estudos da linguística. Mais tarde, Noam Chomsky trouxe de volta tais conceitos a partir da postulação das noções de competência e desempenho. Porém, ele postulou um falante-ouvinte ideal que vivia em uma sociedade de fala em que não havia variação. Vários estudiosos, então, buscaram fundar uma área de estudos que melhor retratasse a realidade linguística. Nesse esforço, Hymes, em 1966, propõe o conceito de competência comunicativa, visto que saber uma língua envolve muito mais que somente conhecer suas regras, mas saber quando e como usá-la. Daí em diante a sociolinguística desenvolveuse, tornando-se um campo de estudos interdisciplinar, que tem trazido grandes contribuições também para o ensino de línguas. Por esta razão, as questões que serão abordadas neste artigo, as quais são objeto do trabalho da pesquisa coletiva do grupo PET de LetrasLíngua Portuguesa, têm como princípio o trabalho com os fenômenos de linguagem a partir dessa nova perspectiva, para a qual apontam os Parâmetros Curriculares Nacionais (PCN). 


\section{Os estudos atuais sobre diversidade e o PET na UFPA}

Os Parâmetros Curriculares Nacionais, publicados pelo Ministério da Educação e do Desporto, em 1998, afirmam que:

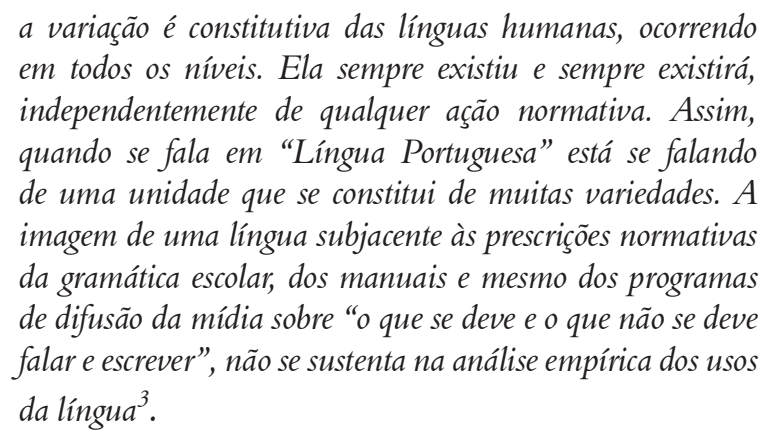

Deste modo, a pesquisa que embasou este artigo teve como objetivos a compreensão da variação como fator universal nas línguas humanas e o conhecimento das diferentes visões e das concepções dos estudiosos do fenômeno da linguagem que levaram em consideração seu aspecto social.

Em vias de eleger essa década como a Década da Educação e da Ciência (2011-2020), Roberto Lent, no Jornal da Ciência (on-line) aponta para o paradoxo que vivemos atualmente no Brasil. O país ocupa o $13^{\circ}$ lugar na produção de artigos científicos em todo o mundo, mas é o último quando se trata do desempenho de jovens de 15 anos em ciências. E o mais grave, na área educacional os indicadores estão estagnados ou sofreram modesta ascensão.

Nesse contexto, em que o ensino básico e o ensino superior parecem tão estanques e separados por imensas discrepâncias, pode-se prestar à comunidade local um conjunto de ações pequenas, mas valiosas, de grupos de pesquisa como o PET, com o intuito de iniciar um ciclo ideológico promotor de mobilização social, por meio da popularização da ciência das linguagens.

${ }^{3}$ Parâmetros curriculares nacionais, Língua Portuguesa, $5^{\text {a }}$ a $8^{\mathrm{a}}$ séries, p. 29. 
O contexto brasileiro, e em particular, o amazônida, é ainda de grande carência de ações que reflitam sobre a educação fundamental, no que concerne ao ensino de língua portuguesa. Com o PET, propomos intervenções que poderão ser ancilares para a construção de um novo patamar na região.

Para isto, articulamos nossas propostas ao Projeto Pedagógico do Curso de Letras da Universidade Federal do Pará.

Esse Projeto Pedagógico do Curso de Letras (PPC de Letras/LP), aprovado pela Resolução CONSEPE No 3.541/2007, articula-se em três eixos: (1) uso da linguagem; (2) reflexão sobre a linguagem; e (3) prática profissional. Com isso, objetiva fornecer oportunidades para que o aluno de Letras: (i) se aproprie de conhecimentos significativos para sua atuação profissional; (ii) reflita sobre a importância e a pertinência desses conhecimentos para a compreensão, o planejamento, a execução e a avaliação de situações de ensino e aprendizagem; (iii) construa uma prática de ensino-aprendizagem com ênfase nos procedimentos de observação e reflexão para compreender e atuar em situações contextualizadas do cotidiano profissional.

De acordo com PPC de Letras/LP, o objetivo do curso é formar profissionais interculturalmente competentes, capazes de lidar, de forma crítica, com as linguagens, especialmente a verbal, nos contextos orais e escritos. O profissional de Letras deve ter domínio do uso da língua ou das línguas, objeto de seus estudos, em termos de sua estrutura, funcionamento e manifestações culturais. Deve ser capaz de refletir teoricamente sobre a linguagem, de fazer uso de recursos tecnológicos e de compreender sua formação profissional como processo contínuo, autônomo e permanente, em que se articulam ensino, pesquisa e extensão. Deve, ainda, ter capacidade de reflexão crítica sobre temas e questões relativas a sua área.

Vale dizer que a diversidade sociolinguístico-cultural, antes de ser um entrave aos processos educacionais, com especial atenção à área de Letras/Língua Portuguesa, deve ser vista como riqueza, e por isso as diferenças precisam ser estudadas e respeitadas.

Urge que o preconceito linguístico, amplamente difundido também por conta da crise no ensino de língua portuguesa, seja desconstruído. Somente dessa forma, alunos oriundos de comunidades populares 
urbanas poderão alcançar os espaços em que o conhecimento acadêmico é predominante, como as universidades. Para alcançar esse objetivo, é necessário dotar os futuros profissionais da área de Letras com saberes, instrumentos didáticos, novas alternativas metodológicas para o ensino da gramática, daí porque a criação do PET é tão imprescindível em nossa região e em nossa universidade.

\section{O Pará da perspectiva linguística}

Pouco se conhece, de forma interligada, acerca dos diferentes aspectos da diversidade e da variação linguísticas no estado do Pará, localizado na região brasileira com a maior concentração de populações de línguas indígenas.

Certamente, cada uma dessas línguas apresenta suas próprias manifestações culturais e literárias várias, o que reflete a diversidade social existente na região, também motivada por desigualdades sociais colossais. Desta forma, um dos objetivos do presente texto é chamar atenção para essa realidade, que deve ser estudada baseada em uma postura de educação sociolinguística, com vistas a ampliar o conhecimento sobre a língua portuguesa regional, sobre as línguas indígenas brasileiras faladas no Pará, bem como sobre a Língua Brasileira de Sinais (LIBRAS).

Apesar das imensas riquezas naturais e de toda a diversidade que constituem a Amazônia, essa região brasileira apresenta um Índice de Desenvolvimento Humano (IDH) ainda muito baixo (0,705), menor que a média nacional que é de $(0,813)$. Esse número mede a "qualidade de vida", reunindo aspectos relativos aos indicadores de renda, longevidade e educação. Desse modo, é factível que os desníveis sociais agudos ainda reinam na Amazônia. Consequentemente, isso reflete os conhecimentos que se tem e que se faz sobre usos linguísticos nas escolas e nas universidades, uma vez que ainda reina em muitas mentes o mito de que o Brasil é um país monolíngue, em língua portuguesa.

De acordo com Weinrich (19XX), as línguas estariam em contato quando utilizadas alternadamente pela mesma pessoa (sujeito bilíngue). Thomason e Kaufman (1988, p. 3) afirmam que há duas situações de contato bem distintas que podem levar ao surgimento de línguas mistas. Tais situações são geralmente diferençadas como casos de interferência 
de empréstimo e de substrato, o que, segundo esses pesquisadores, influencia sobremaneira nos resultados linguísticos.

Segundo Aikhenvald (2002, p. 1), o grande desafio para os linguistas interessados em trabalhar na área de linguística comparativa é justamente distinguir aquelas semelhanças devidas à herança genética e aquelas devidas ao empréstimo. É o caso de traços linguísticos abertos ou não à difusão.

Para além da discussão acerca de definir ou não o estado do Pará como uma micro-área linguística, considerando-se a definição de Campbell, Kaufman \& Smith-Stark (1986) para a Meso-América, podese afirmar que a situação de contato entre as línguas indígenas no Pará refere-se a séculos sem documentação ou com documentação espalhada, encontrada na literatura dos viajantes. Deste modo, o objetivo deste trabalho é também apresentar um panorama sobre as línguas indígenas faladas no estado do Pará, a partir de informações contidas nos materiais escritos de linguistas que vêm trabalhando na descrição dessas línguas. A imensidão da tarefa não possibilita a apresentação de conclusões ou de refinamentos sobre o tema por ora, uma vez que, para tal, é necessário compreender a riqueza que cada situação de contato individualmente pode trazer à teoria linguística. Deste modo, limitamos nossa tarefa a enumerar quais são as línguas faladas no Pará.

\subsection{Caracterização do estado do Pará e as línguas faladas na região}

O estado do Pará é o segundo maior do Brasil em extensão. São 1.253.165 $\mathrm{Km}^{2}$, o que representa 14,66\% do território nacional. Está constituído por 143 municípios e localiza-se ao centro da região Norte. Nesta área geográfica francamente amazônica concentram-se a língua portuguesa, cerca de 25 línguas indígenas de três troncos linguísticos (Macro-Jê, Tupi e Família Karib), além de línguas menos antigas na região, como o japonês, falado no município de Tomé-Açu, norte do estado, a 260 quilômetros da capital.

Com base nas fontes contidas nos materiais de Queixalós e RenaultLescure (2000), Moore, Galúcio e Gabas (2008), Seki (2000), bem como no sítio do Instituto Sócio-Ambiental, as línguas indígenas faladas no 
estado são apresentadas abaixo com informações sobre a afiliação genética, o município em que está(ão) localizada(s) a(s) comunidade(s) que as fala(falam-nas) e o número de falantes (quase sempre controverso).

\begin{tabular}{|c|c|c|c|}
\hline $\begin{array}{l}\text { GRUPO/ } \\
\text { COMUNI- } \\
\text { DADE }\end{array}$ & LOCALIZAÇÃO & $\begin{array}{c}\text { TRONCO } \\
\text { LINGUÍS- } \\
\text { TICO }\end{array}$ & $\begin{array}{l}\text { FAMÍLIA } \\
\text { LINGUÍS- } \\
\text { TICA }\end{array}$ \\
\hline $\begin{array}{l}\text { Parakanã } \\
\text { (dividido } \\
\text { em duas } \\
\text { comunidades) }\end{array}$ & $\begin{array}{l}\text { Uma das duas comunidades, chamada } \\
\text { Terra Indígena Parakanã, fica localizada } \\
\text { entre os municípios de Itupiranga e Novo } \\
\text { Repartimento; e a outra, conhecida como } \\
\text { Área Indígena Apyterewa, situa-se entre os } \\
\text { municípios de Senador José Porfírio e São } \\
\text { Félix do Xingu. }\end{array}$ & Tupi & Tupi-Guarani \\
\hline Araweté & $\begin{array}{l}\text { Localizado na região do rio Ipixuna, no } \\
\text { médio rio Xingu, numa área que abrange } \\
\text { os municípios de Altamira, São Félix do } \\
\text { Xingu e Senador José Porfírio. }\end{array}$ & Tupi & Tupi-Guarani \\
\hline Tembé & $\begin{array}{c}\text { Localizados nas aldeias Sede e São Pedro, } \\
\text { próximo ao Rio Guamá, nas Terras } \\
\text { Indígenas Turé-Mariquita e Tembé } \\
\text { (município de Tomé-Açu). }\end{array}$ & Tupi & Tupi-Guarani \\
\hline Xipaya & Estão na cidade de Altamira. & Tupi & Juruna \\
\hline Xikrin & $\begin{array}{c}\text { Vivem em duas áreas distintas: uma } \\
\text { localizada no município de Parauapebas, } \\
\text { e a outra no município de Senador José } \\
\text { Porfírio. }\end{array}$ & Macro-Jê & Jê \\
\hline Parkatejê & $\begin{array}{l}\text { Comunidade localizada no município de } \\
\text { Bom Jesus do Tocantins. }\end{array}$ & Macro-Jê & Jê \\
\hline $\begin{array}{l}\text { Menkrangnoti } \\
\text { (Kayapó) }\end{array}$ & $\begin{array}{l}\text { Localizam-se numa grande área contígua } \\
\text { que se estende do norte do Mato Grosso à } \\
\text { região sul do Pará. }\end{array}$ & Macro-Jê & Jê \\
\hline Munduruku & $\begin{array}{l}\text { Vivem no vale do rio Tapajós e de } \\
\text { seus afluentes, no estado do Pará - } \\
\text { atualmente concentrados na terra indígena } \\
\text { Munduruku, município de Jacareacanga. } \\
\text { Sendo também encontrados na bacia do } \\
\text { Rio Madeira, Estado do Amazonas, e na } \\
\text { terra indígena Apiaká, município de Juara } \\
\text { (Mato Grosso). }\end{array}$ & Tupi & Munduruku \\
\hline
\end{tabular}




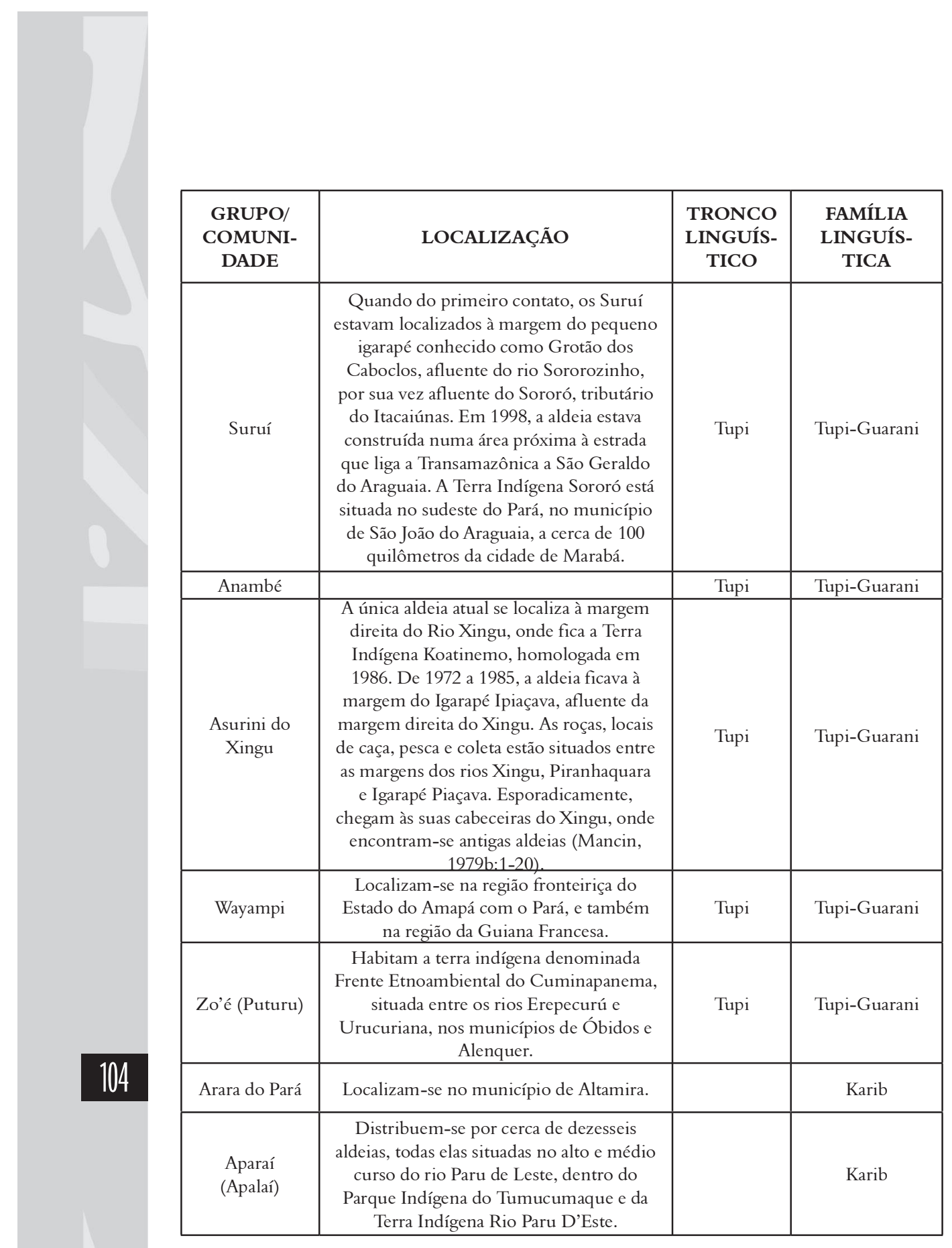


Muitas comunidades indígenas localizadas no Pará, à exceção do povo Zo'é, que é isolado, vivem em situação de línguas em contato, em que indivíduos falantes dessas línguas nativas conhecem e utilizam a língua portuguesa para interagir com a sociedade envolvente. De acordo com Aikhenvald (2002, p. 1), em uma situação de línguas em contato, os falantes de uma língua têm algum conhecimento da outra língua, e, dessa forma, podem emprestar traços linguísticos, como hábitos de pronúncia, fonemas, categorias gramaticais, itens vocabulares e mesmo algumas formas gramaticais. Deste modo, as línguas podem apresentar similaridades devido à difusão de características linguísticas.

\section{Línguas e estudos já feitos}

\section{Parakanã:}

SILVA, Gino F. da. "Construindo um dicionário Parakanã-Português". Dissertação de Mestrado. UFPA. Belém, 2003.

\section{Araweté:}

ALVES, Juliana F. "Fonética e Fonologia da língua Araweté: uma nova contribuição". Dissertação de mestrado. UnB. Brasília, 2008.

\section{Tembé:}

DUARTE, Fábio Bonfim. "Análise Gramatical das orações da língua Tembé”. Dissertação de mestrado. UnB. Brasília, 1997.

CARVALHO, Márcia Goretti Pereira de. "Sinais de morte ou de vitalidade? Mudanças estruturais na língua Tembé". Dissertação de mestrado. UFPA. Belém, 2001.

\section{Xipaya:}

FARGETTI, Cristina M.; RODRIGUES, Carmen L. Reis. "Consoantes do Xipaya e do Juruna - uma comparação em busca do proto-sistema”. Alfa: Revista de Linguística. Araraquara, São Paulo, 2008. p. 535-563.

RODRIGUES, Carmen Lúcia Reis. "Étude morphosyntaxique de la langue Xipaya”. Tese de doutorado. Paris, 1995.

\section{Xikrin:}

COSTA, Lucivaldo S. da."Flexão relacional, marcas pessoais e tipos de predicados em Xikrín: contribuição para os estudos sobre ergatividade em línguas Jê”. Dissertação de mestrado. Belém, 2003. 


\section{Parkatêjê:}

FERREIRA, Marília de Nazaré de Oliveira. "Estudo Morfossintático da Língua Parkatejê". Tese de doutorado. Campinas, 2003.

ARAÚJO, Leopoldina Maria Souza de. "Estruturas subjacentes de alguns tipos de frases declarativas afirmativas do dialeto Gavião-Jê”. Dissertação de mestrado. Florianópolis, 1977.

.Aspectos da língua Gavião-Jê". Tese de doutorado. Rio de Janeiro, 1989.

Mebengôkre (Kayapó):

SILVA, Maria Amélia Reis. "Pronomes, Ordem e Ergatividade em Mebengôkrê (Kayapó)”. Dissertação de mestrado. Campinas, 2001.

\section{Munduruku:}

ANGOTTI, Mary Lourdes de Oliveira. "A causativização em Munduruku: aspectos morfo-sintáticos”. Dissertação de mestrado. Brasília, 1998.

GOMES, Dioney Moreira. "Estudo morfológico e sintático da língua Munduruku”. Tese de doutorado. Brasília, 2006.

PICANÇO, Gessiane Lobato.

Wayampi:

JENSEN, Cheryl Joyce S. "O desenvolvimento histórico da língua Wayampi”. Dissertação de mestrado. Campinas, 1984.

\section{Zo'é:}

CABRAL, A.S.A.C. Notas sobre a fonologia segmental dos Jo'é. Moara, Revista dos Cursos e Pós Graduação em Letras/ UFPA, Belém, n. 4, p. 23-45, 1996.

\section{Arara (Karib):}

SOUZA, Isaac Costa de. "Contribuição para a fonologia da língua Arara (Karib)". Dissertação de mestrado. Campinas, 1988.

\section{Conclusão}

A diversidade linguística é atestada na região amazônica e requer um olhar mais minucioso e crítico acerca dessa pluralidade de "línguas" que ainda são muito desconhecidas, tanto no contexto amazônico quanto em nível nacional. Observa-se que ainda reina no Brasil um sentimento de monolinguismo em língua portuguesa. 
A finalidade do presente artigo foi principalmente documentar uma parte, ainda que mínima, da variedade linguística existente na região amazônica. Só no estado do Pará são faladas cerca de vinte e cinco línguas indígenas, mais diversas variedades de língua portuguesa amazônica, bem como a de LIBRAS. Enfatizamos com maior atenção na tabela a diversidade de línguas indígenas, uma vez que várias delas encontram-se em perigo de extinção por causa do contato com a língua majoritária do país.

Acreditamos que atividades (in)formativas sobre essa grande diversidade linguística podem contribuir para a erradicação do preconceito linguístico, enfatizando sua importância nos cursos de licenciatura que formam professores para atuar no ensino fundamental. É importante frisar também que esse conhecimento deve ser levado às comunidades populares, afinal falamos línguas diferentes no Brasil, cada uma com importante carga cultural na formação de nosso povo.

\section{REFERÊNCIAS}

AIKHENVALD, Alexandra Y. Language Contact in Amazônia. Oxford: Oxford University Press, 2002.

BRASIL. Secretaria de Educação Fundamental. Parâmetros curriculares nacionais: terceiro e quarto ciclos: apresentação dos temas transversais/Secretaria de Educação Fundamental. Brasília: MEC/SEF, 1998.

CAMPBELL, Lyle; KAUFMAN, Terence; SMITH-STARK, Thomas C. Meso-America as a linguistic area. Language. v. 62, n.3,1986.p.530-558. QUEIXALÓ, F.; RENAULT-LESCURE, O. (Org.). As Línguas Amazônicas Hoje. São Paulo: IRD/ISA/MPEG, 2000.

ISA. Povos Indígenas no Brasil 2001/2005. São Paulo: Instituto Socioambiental, 2006.

MOORE, Denny; Galucio, Ana Vilacy; Gabas Junior, Nilson. O desafio de documentar e preservar as línguas amazônicas. Scientific American 
Brasil (Edição Especial). Amazônia: A Floresta e o Futuro, v. 3, set., 2008. p. 36-43.

SEKI, Lucy. A linguística indígena no Brasil. Linguística, revista da ALFAL. Campinas, 1999.

SEKI, Lucy. Línguas indígenas do Brasil no limiar do século XXI. Impulso, 2000.

THOMASON, Sarah G.; KAUFMAN, Terrence. Language Contact, Creolization and Genetic Linguistics. Berkeley: University of California Press, 1988.

WEINREICH, Uriel. Language in contact. New York: Reprint, The Hague, 1963. 